\title{
Non-Functional Requirements Research: Survey
}

\author{
Harsimran Kaur, \\ ASU, Gurgaon
}

\author{
Dr. Ashish Sharma \\ GLA University, Mathura
}

\begin{abstract}
NFRs are important since the system architecture greatly depends on the NFRs [20]. Mostly NFR Literature has considered only for key challenges and issues related to NFR. In context of such a need a roadmap for important issues is required. In this paper survey has been presented on interesting ongoing work in the field of non functional requirements and tried to figure out the approaches and methods that are suggested in literature to deal with these issues.
\end{abstract}

Index Terms- Non Functional Requirements, Modeling, Identification, Formalization, Quantification, Automation

\section{INTRODUCTION}

IEEE Definition: "non functional requirement (NFR) - in software system engineering, a software requirement that describes not what the software will do, but how the software will do it, for example, software performance requirements, software external interface requirements, design constraints, and software quality attributes. Nonfunctional requirements are difficult to test; therefore, they are usually evaluated subjectively" [50]. In the past relatively little attention has been paid to the process of systematically dealing with NFR's and developers have relied mostly on their own intuitions, in an ad hoc way. In the years, the topic has attracted increasing interest from researchers, as testified by the many specialized events and workshops, as well as by the growing percentage of NFR papers in software engineering conferences.

There has been a considerable increase in the quantity of NFR research over the past few years (see Figure 1(b)). Despite the excellent work in the surveys listed earlier, there remains, to date, no comprehensive survey of the whole field of study concerning trends in research. This paper provides a range of options (Road map) for future research in area of non functional requirements.

The paper is organized as follows: Section 2 describes the result summary of the literature survey. Section 3 discusses the eight categories of research, and reviews the contributions from various research groups and the growing trend. Section 4 presents the conclusion and Future Work.

\section{CLASSIFICATION SCHEME}

The goal of our paper is to categorize the issues of NFR. We used the five digital libraries to search: ACM Digital Library, SpringerLink, ScienceDirect, Google Scholar, IEEE Xplore, ACM Digital Library, We classify these papers into eight categories.

1. Identification and Specification: Studies on notion(facet), classification and types of NFR.

2. Elicitation: Studies on requirements elicitation methods to empower requirement centered on NFRs.
3. Modeling (Informal): Studies on an approach to record and model non-functional requirements using UML and Relational Diagrams.

4. Modeling (formal): Studies on semantic concepts for the specification of non functional properties.

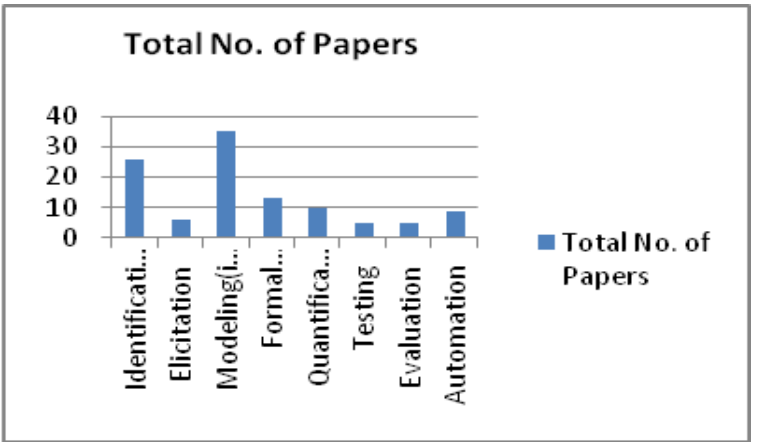

Fig 1(a) Paper in each category

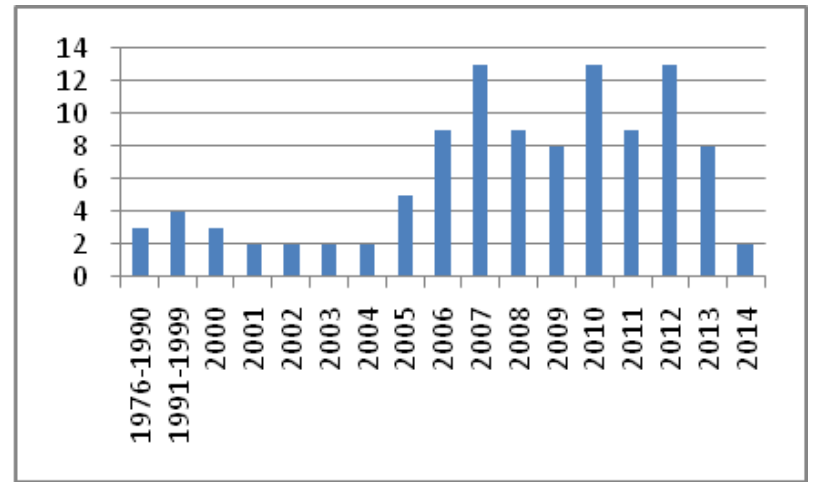

Fig 1(b) NFR Publication growth overtime

Quantification: Studies which explore number of avenues related to specification, design which deals and effect quantification of NFR.

5. Testing: Studies on issues, challenges while consider NFR, resulting from quality concern of stakeholders. 
6. Automation: Studies on tools that assist the requirement Analyst while dealing with NFRs.

7. Evaluation: Studies on the degree to which NFR contributes to the improvement of software quality.

Assignment of category to each paper has been based on the main objective of the paper. Thus, in our classification some papers may be into another category by other researchers. For example many of the papers related to elicitation are presented by using any modeling language so we put them in the category of Modelling. Similarly identification and elicitation can be done by a single approach but we put them in different categories on the basis of focused concept used in the paper are Figure 1(a) shows the proportion of papers that fall into each of the different NFR area subject categories while Figure 1(b) shows the histogram charting NFR publication growth over time,

\section{LITERATURE REVIEW}

\section{A. Identification and Specification}

We surveyed different definitions and classification schemes proposed by different researchers. Critical Evaluation has been done as shown in Table 1. No Formal definition for NFR is found in literature except this: $\mathrm{f}: \mathrm{I} \rightarrow \mathrm{O}$ (e.g., sum: int $\mathrm{x}$ int $\rightarrow$ int) which is defined by Chung etal [23]. NFR Framework is one of the prominent works that has been done in this field. For the specification of NFR there are three categories of approaches available in literature as shown in table 2. NFR Framework is the one of the important work which later on extended by number of researchers in order to solve the problem in their application domain [70]. Beside NFR Framework KAOS [103] and work with the help of UML has been found in literature which we are going to discussed in modelling. Formal language for NFR becomes a necessity but a familiar problem with formal methods in specifying such requirements is the high cost and difficulty of using them. Some of the work on formalization is shown in Table 2. There are few papers on the formal specification languages. Methods of supervised learning have been proposed in the literature to address the problem of identification and classification of NFR. Within the ECSS, ISO, and IEEE standards, a number of views and concepts are provided to describe various types of candidate portability requirements at the system, software, and hardware level [2].

\section{B. Elicitation}

There are only very few approaches and tools to elicit NFR. Many of the techniques and tools available are for functional requirements. Classification for the approaches used in elicitation of NFR as shown in Table 3 is based on different categories of approaches [108][116]. Ullah etal. has identified several key issues like conflicts of requirements, integration of NFR with FR and ambiguous specification of system features. They have found some of the solutions of these stated problems based on the available literature.

\section{Modelling (informal)}

A survey of the different works shows that most of them use UML with some extensions to add NFRs with the functional requirements models as shown in Table 4. UML proven to be successful modelling language to bring the revolution in NFR specification and modelling. Number of tools like Rational Rose, Smart Draw and Enterprise architect are available for UML.There are other approaches like Relational Model, Petrinets, Multimodel, NFR Framework, NFR Framework + that can be used to specify NFRs as mentioned in Table 4.

\section{Formal Modelling}

Formal methods offer a mathematical way to specify and analyze the behavior of NFR in a system together with a related tool support. Some relevant work done in this field by different researchers is discussed below. UML-B has been used for a real-time control system security concerns using an action systems approach [98]. There is requirement of tool support for UML-B. RoZ tool is used for modelling the airport security. It uses Z notation [63]. Another approach called KAMI is implemented as a distributed framework with a plugin architecture, which allows new tools to be incorporated to support other modeling notations and analysis procedures [34]. The approach is based on formal (probabilistic) models that are used at design time to reason about dependability of the application in quantitative terms. Another approach based on semantic concepts which form the basis of a semantic framework for the specification non-functional properties of component-based software [126][127]. Probabilistic way of characterizing the implementation of software non-functional requirements is proposed in [114]. SysML has been adopted as the modeling language by [107], since it enables requirement definition and can be formally extended. [90] has presented a semiformal approach for reasoning and refining functional requirements. Non Functional properties has expressed as NFactions, NF-statements and NF-attribute. An another approach [83] aimed at lessen the risk of such misuses of quality models. It is centered on the definition of a language called NoFun which is to be used as a formal language for the exhaustive description of software quality. Borges and Mota [16] integrate UML class diagrams and OhCircus by written UML elements in terms of OhCircus constructs. OhCircus is a formal specification language which uses Z, CSP, calculus of Morgan and object-oriented theories. Casamayor [19, 20] propose a semi-supervised text categorization approach for the automatic identification and classification of non-functional requirements. Detection and classification of NFRs is performed using semi-supervised learning techniques. One more interesting work is shown in [26] which discuss an algebraic formalization of model based on graph theory which they use to prove safe termination in systems compliant with Ravenscar Computation Model ( RCM), and show how to use the MAST+ static analyzer to verify the timing aspects. But till lot of work need to be done in this direction as mentioned in [19][21][23]. 
Table 1. Different Classification Schemes Proposed in Literature

\begin{tabular}{|c|c|c|}
\hline Source & Research proposal & Critical Evaluation \\
\hline Boehm(1976)[14] & $\begin{array}{l}\text { Paper provides for the first time a clear, well-defined } \\
\text { framework for assessing the often slippery issues } \\
\text { associated with software quality, via the consistent and } \\
\text { mutually supportive sets of definitions, distinctions and } \\
\text { guidelines [14]. }\end{array}$ & $\begin{array}{l}\text { No emphasis has been found } \\
\text { attributes of those NFRs. }\end{array}$ \\
\hline McCall(1980)[72] & $\begin{array}{l}\text { A Software Quality Measurement Manual was } \\
\text { produced which contained procedures and guidelines } \\
\text { for assisting software system developers in setting } \\
\text { quality goals, applying metrics and making quality } \\
\text { assessments. }\end{array}$ & $\begin{array}{l}\text { It was assumed to be efficient } \\
\text { model. Later it modified in } 2000 \\
\text { where requirements are classified on } \\
\text { the basis of product revision and } \\
\text { transition. }\end{array}$ \\
\hline $\begin{array}{lr}\text { Roman } & \text { IEEE } \\
\text { Computer } & (1985) \\
{[88]} & \end{array}$ & $\begin{array}{l}\text { It classifies requirements into interface, performance, } \\
\text { operating, lifecycle, economic and political } \\
\text { requirements. }\end{array}$ & It is complex classification. \\
\hline $\begin{array}{l}\text { Sommerville } \\
\text { (1992) [100] }\end{array}$ & $\begin{array}{l}\text { It considers organization, product and external aspects } \\
\text { of requirement. }\end{array}$ & $\begin{array}{l}\text { This model is accepted by many } \\
\text { organizations but it could not sort } \\
\text { the Non Functional Requirement } \\
\text { specification issues. }\end{array}$ \\
\hline Grady(1992)[42] & $\begin{array}{l}\text { FURPS and FURPS+ is an acronym that represents the } \\
\text { model. It introduces dimensions of quality. }\end{array}$ & $\begin{array}{l}\text { Architectural integrity is not covered } \\
\text { in the model }\end{array}$ \\
\hline $\begin{array}{l}\text { ISO/IEC } 9126 \\
(2001)[52]\end{array}$ & $\begin{array}{l}\text { Distinguishes four types of quality levels } \\
\text { Quality in use, external quality, internal quality and } \\
\text { process quality which helps to provide process oriented } \\
\text { classification. }\end{array}$ & $\begin{array}{l}\text { It sets standard for software } \\
\text { practitioner to make the meaning of } \\
\text { NFR and important NFR like } \\
\text { performance clear to developers and } \\
\text { users. But it is only limited to few } \\
\text { NFRs. }\end{array}$ \\
\hline $\begin{array}{l}\text { Martin Glinz } \\
(2005)[39]\end{array}$ & $\begin{array}{l}\text { Presents New Classification of Requirements } \\
\text { - } \quad \text { Kind } \\
\text { - } \text { Representation } \\
\text { - Satisfaction } \\
\text { - Role }\end{array}$ & $\begin{array}{l}\text { Provides new notion to the NFRs but } \\
\text { classification has no practical } \\
\text { usefulness in daily life. It can be } \\
\text { simplified further. }\end{array}$ \\
\hline $\begin{array}{l}\text { Jureta etal.(2006) } \\
\text { [57] }\end{array}$ & $\begin{array}{l}\text { This classification provides four categories: functional } \\
\text { hardgoal, non functional hardgoal, functional softgoal } \\
\text { and nonfunctional softgoal. }\end{array}$ & $\begin{array}{l}\text { It is driven by nonfunctional } \\
\text { perspective. }\end{array}$ \\
\hline $\begin{array}{l}\text { Martin Glinz } \\
(2007)[40]\end{array}$ & $\begin{array}{l}\text { Proposed New Definition to requirements and Specify } \\
\text { classification rules based on Aspect-Oriented } \\
\text { Representation. }\end{array}$ & $\begin{array}{l}\text { Definition and Classification is less } \\
\text { ambiguous than traditional } \\
\text { definitions. Its Practical aspect needs } \\
\text { to be find out. }\end{array}$ \\
\hline $\begin{array}{l}\text { Dewi Mairiza } \\
\text { etal.(2010) [70] }\end{array}$ & $\begin{array}{l}\text { It offers a novel classification of NFRs types based on } \\
\text { types of systems and application domains. }\end{array}$ & $\begin{array}{l}\text { It presents comprehensive lists of } \\
\text { NFR types which helps developer to } \\
\text { identify NFR for their particular } \\
\text { system. But the Terminology present } \\
\text { does not improve the notion of } \\
\text { NFRs. }\end{array}$ \\
\hline $\begin{array}{l}\text { Chi-Lun Liu } \\
(2010)[66]\end{array}$ & $\begin{array}{l}\text { Proposes top level NFR ontology helpful in conflict } \\
\text { detection between NFRs which is extended from } \\
\text { Glinz's study. }\end{array}$ & $\begin{array}{l}\text { Nothing has been done for } \\
\text { improving NFR facet in it. }\end{array}$ \\
\hline
\end{tabular}

Table 2: Categorization of Approaches used in Identification

\begin{tabular}{|c|c|c|c|c|c|c|c|c|c|c|c|c|c|c|c|c|c|c|c|c|c|c|}
\hline & $\Xi$ & $F_{\infty}$ & e & E & $\vec{E}$ & N & 节 & $\mathbb{\infty}_{\infty}$ & $\tilde{E}$ & N & تر & J & Fo & $\mathbb{E}$ & $E$ & $\underset{\infty}{\infty}$ & 5 & 5 & $\underline{E}$ & 冓 & ت & $\vec{E}$ \\
\hline Informal Approach(I) & $\mathrm{I}$ & & & & $\mathrm{I}$ & $\mathrm{I}$ & $\mathrm{I}$ & $\mathrm{I}$ & I & & & & $\mathrm{I}$ & $\mathrm{I}$ & I & $\mathrm{I}$ & & & $\mathrm{I}$ & $\mathrm{I}$ & & \\
\hline Semi-Formal Approach(S) & & & $\mathrm{S}$ & $\mathrm{S}$ & & & & & & & & & & & & & $\mathrm{S}$ & S & & & & \\
\hline Formal Approach(F) & & $\mathrm{F}$ & & & & & & & & $\mathrm{F}$ & $\mathrm{F}$ & $\mathrm{F}$ & & & & & & & & & $\mathrm{F}$ & $\mathrm{F}$ \\
\hline
\end{tabular}


Table 3: Classification of approaches used in elicitation of NFRs

\begin{tabular}{|l|l|l|}
\hline Approaches & References & Description \\
\hline NFR Framework Based & {$[4][27][48][84][101]$} & $\begin{array}{l}\text { Process-oriented and qualitative method for } \\
\text { handling NFRs }\end{array}$ \\
\hline Quality Model Based & {$[6][9][52][58][104]$} & $\begin{array}{l}\text { NFR method consists of quality attributes, } \\
\text { based on quality model }\end{array}$ \\
\hline $\begin{array}{l}\text { NFR Framework with Quality Model } \\
\text { Based }\end{array}$ & {$[52][56][58][121]$} & $\begin{array}{l}\text { i* framework and meta-model are presented in } \\
\text { these approach. }\end{array}$ \\
\hline $\begin{array}{l}\text { Guideline Based Framework and } \\
\text { (Without NFR Framed on gathering } \\
\text { Quality Model Based }\end{array}$ & {$[51][111]$} & $\begin{array}{l}\text { Approaches set the and focused on } \\
\text { only the minimum set of information on quality } \\
\text { goals. }\end{array}$ \\
\hline
\end{tabular}

Table 4: Informal Modelling of NFR

\begin{tabular}{|c|c|}
\hline Approach(Model) & Purposed \\
\hline $\begin{array}{l}\text { Use Case and Goal Driven } \\
(2005)[103]\end{array}$ & Integrates FR with NFR at design level by using use case elements. \\
\hline Extended Use Case (2006)[11] & $\begin{array}{l}\text { To separate(cross-cut) the concerns at the requirements level(on tha basis of } \\
\text { application domain) that can be achieved by checking concerns that produce } \\
\text { spread and tangled representation that are difficult to understand and maintain. } \\
\text { Extended elements helps to express and integrate NFR and challenges to } \\
\text { requirement analyst with the FR. }\end{array}$ \\
\hline OONFR(2001) [26][27] & $\begin{array}{l}\text { UML Class Diagram is proposed which use LEL of UofD as input and class } \\
\text { diagram has signals of what elements (classes, attributes, operations and } \\
\text { relationship) are responsible for NFR. }\end{array}$ \\
\hline Extended UML(2007)[123] & Dependency notation is introduced in UML to model design decisions. \\
\hline $\begin{array}{l}\text { Extending UML with NFR } \\
\text { Framework(2005)[22][23] }\end{array}$ & $\begin{array}{l}\text { Meta-Model to represent concepts in NFR Framework and made extension in } \\
\text { UML and NFR Framework to integrate the notations of two modeling languages. }\end{array}$ \\
\hline $\begin{array}{l}\text { Novel Framework with } \\
\text { UML(2005)[106] }\end{array}$ & $\begin{array}{l}\text { UML design is integrated to NFRs for the purpose of reengineering process of } \\
\text { legacy systems. }\end{array}$ \\
\hline $\begin{array}{lr}\text { Layered } & \text { Model(Conceptual } \\
\text { ArchitecturalModel)(2005)[117] }\end{array}$ & $\begin{array}{l}\text { Additional layer is added to traditional architectural model for satisfying NFR } \\
\text { Role. }\end{array}$ \\
\hline UMLsec (2002) [53] & $\begin{array}{l}\text { UML extension mechanism based on formal semantics to evaluate security } \\
\text { aspects of system design }\end{array}$ \\
\hline SecureUML (2002) [68] & $\begin{array}{l}\text { UMl extension mechanism to specify information for access control in the design } \\
\text { of application. }\end{array}$ \\
\hline Abuse Case Model(2002)[68] & $\begin{array}{l}\text { Extended Use Case Model to capture and analyze security requirements by } \\
\text { specifying check on interaction between system and actors. }\end{array}$ \\
\hline Architectural pattern(2005) [61] & $\begin{array}{c}\text { Improving system dependability and trustworthiness by improving the modeling } \\
\text { of NFR(operationalizable NFRs, and checkable NFRs) }\end{array}$ \\
\hline $\begin{array}{l}\text { NFR Framework with Role } \\
\text { Activity Model (2007)[3] }\end{array}$ & $\begin{array}{l}\text { Remodelling business process to better representation and realization of NFR } \\
\text { aspects of processes by linking RAD with NFR graphic facility. }\end{array}$ \\
\hline $\begin{array}{l}\text { Use Case extended to Control } \\
\text { Case(2006)[114][124] }\end{array}$ & $\begin{array}{l}\text { Focus is made on operating conditions by adding control cases to } 4+2 \text { view of } \\
\text { architecture(UML Process view) }\end{array}$ \\
\hline DERAF(2007) [69] & $\begin{array}{l}\text { Combines the use of aspects with RT-UML, aiming to separate the handling of } \\
\text { non-functional from functional requirements in the Model Driven Design of } \\
\text { DERTS. }\end{array}$ \\
\hline Integrated Model(2007) [113] & $\begin{array}{l}\text { Approach is based on building a base quality model that relies on an explicit } \\
\text { meta-model. Purpose models are also needed to support the planning and } \\
\text { realization of quality assurance are derived from the base model by quantifying } \\
\text { the relations modeled in the base model. }\end{array}$ \\
\hline XML-NFR(2007) [ & is also step to integrate with functional requirements design model based on \\
\hline
\end{tabular}




\begin{tabular}{|c|c|}
\hline & simple language XML but not solved many issues of NFR. \\
\hline $\begin{array}{l}\text { Pluggable Framework (Wireless } \\
\text { Sensor networks)(2008) [15] }\end{array}$ & $\begin{array}{l}\text { It allows WSN applications in TinyDDS(Data Distributed Services) to have fine- } \\
\text { grained control over non-functional properties and specialize in their own } \\
\text { requirements. }\end{array}$ \\
\hline RASF(2008) [45] & $\begin{array}{l}\text { A Multi-Agent Systems (MAS) approach in Reactive Autonomic Systems (RAS) } \\
\text { whose specifications are mentioned in single formal framework. }\end{array}$ \\
\hline XML with Petri-Nets(2008)[31] & $\begin{array}{l}\text { The intermediate model is based on XML and indicates the relationship between } \\
\text { the entities of design models and analysis models by minimizing the gaps }\end{array}$ \\
\hline $\begin{array}{l}\text { Extended PLUS (UML Based } \\
\text { Model) (2009) [79] }\end{array}$ & $\begin{array}{l}\text { It provide a unified and systematic framework for analysis modeling of NFRs in } \\
\text { Software Product Lines by integrating it with Lines PLUS. }\end{array}$ \\
\hline SysML(2009)[107] & $\begin{array}{l}\text { It represents NFR as how non-functional requirements are related between them } \\
\text { and to system components forming the overall system architecture. }\end{array}$ \\
\hline KAMI(2009) [38][103] & $\begin{array}{l}\text { Approach relies on run-time monitoring and uses the data collected by the } \\
\text { probes to detect if the behavior of the open environment in which the application } \\
\text { is situated can lead to a failure of the application }\end{array}$ \\
\hline NFR with AORE(2010)[114] & $\begin{array}{l}\text { It map non-functional requirements into function and architectures through non- } \\
\text { functional scenario template which improves traceability from requirement } \\
\text { analysis level to implement level. }\end{array}$ \\
\hline $\begin{array}{l}\text { Configuration Models(2012) } \\
\text { [33] }\end{array}$ & $\begin{array}{l}\text { Mapping nonfunctional aspects to given commercial-off-the-shelf modules } \\
\text { which makes possible the integration of commercial software modules into } \\
\text { product } \\
\text { families }\end{array}$ \\
\hline Relational Model (2011) [59] & $\begin{array}{l}\text { It introduce change management mechanism that trace the the impact of NFRs } \\
\text { on the other constructs in the ontology such as FR or NFR operationalization and } \\
\text { vice versa. }\end{array}$ \\
\hline $\begin{array}{l}\text { Multimodel Approach(2012) } \\
\text { [41] }\end{array}$ & $\begin{array}{l}\text { Besides the refinement of NFR it allows the validation of its fulfillment through } \\
\text { the application of metrics that are associated to each NFR. }\end{array}$ \\
\hline $\begin{array}{l}\text { Design } \\
\text { Approach }(2001)\end{array}$ & $\begin{array}{l}\text { It provides guidance and reasoning support when applying patterns } \\
\text { during the design of a software system. }\end{array}$ \\
\hline UML with OCL [83] & $\begin{array}{l}\text { Non functionality is described by means of a notation called NoFun, which } \\
\text { allows us to introduce non-functional attributes of software }\end{array}$ \\
\hline $\begin{array}{l}\text { UML Based on EAST-ADL } \\
\text { (2011) [91] }\end{array}$ & $\begin{array}{l}\text { Provides solution for telecommunication systems for modeling product families, } \\
\text { targeting cost sensitivity non-functional requirements and performing cost } \\
\text { analysis. }\end{array}$ \\
\hline $\begin{array}{l}\text { Domain Specific } \quad \text { Modelling } \\
\text { Approach(NFR+ Framework) } \\
{[119]}\end{array}$ & $\begin{array}{l}\text { The solution enables a full bi-directional traceability from the requirements to } \\
\text { models to the implementation. }\end{array}$ \\
\hline $\begin{array}{l}\text { UML for } \quad \text { intrusion } \\
\text { specification(2006) [49] }\end{array}$ & $\begin{array}{l}\text { UML notations extended to suit the context of intrusion scenarios that allows } \\
\text { developers to specify intrusions }\end{array}$ \\
\hline
\end{tabular}

\section{E. Quanitification}

There are very few languages to state non-functionality in form so that it can be quantified. One of the language [35][83] is NoFun which provides a common framework in which people can formulate, analyse and compare their proposals about non-functionality. A measure for reusability is refined by this language.The combination of both NoFun and the implementation selection algorithm can be an aid to software specification, design, reusability and maintenance. Stephan Jacobs [54] of Ericsson presented a case study on improving requirement engineering. From the concepts offered in Planguage Jacobs proposed that Gist, Scale, Meter, Past, Record, Must, Plan and Wish should be made visible in our requirements specifications by using keywords in bold letters. GIST is a rough summary of the requirement. According to Jacobs SCALE defines the unit in which the requirements has to be measured. METER defines the way how the measurement will be performed. PAST and RECORD are benchmarks. Past is a value which is typical for (own) products developed in the past. MUST, PLAN and WISH envisage the future. Must, Plan and Wish characterize the system that is to be built. Affleck [5] extends the previous quantitative reasoning extension into a single objective optimization model that aims to selectively choose operationalizations in order to increase the overall satisfaction of non-functional requirements. One metric is proposed in [1] 
that can be used in the early stages of software development projects to estimate effort of new projects. Affleck [4] presents a process-orientated, lightweight, quantitative extension to the NFR Framework; focusing on providing quantitative support to the decision process and how decisions affect the system. Some key issues related to NFR quantification are discussed in [85][90].They discussed issues related to sharing of information between customer and supplier as it is must for optimal quantification. Requirements Convergence Plan can be used to create better NFR quantification circumstances for customers and suppliers. Another evaluation model of NFR is proposed in [94] which mainly focusing on the user maintenance and operation issues. This model consists of NFR categories, NFR metrics, description level grading and weight to each NFR. Another contribution to quantification of NFR is made by Bin [119] by proposing three methods for calculating non-functional properties. The cumulative method is applied to calculation of energy cost, memory cost, and number of defects and so on. The multiplicative method is applied to calculation of non-functional properties which can be described by probability, such as reliability, confidentiality. The graphic method is applied to calculation of consumed time. Paper also proposes a 0-1 programming method for selecting the best non-functional requirement implementation strategies. Bhatti etal.[13] tries to quality metrics on the basis of UML diagrams.

\section{F. Testing}

[97] has mentioned prevalent testing issues in the light of NFR. There is a great need to work on specification for testability, design for testability and code for testability as mentioned in previous sections of paper. They also mention certain research direction for future exploration in their paper. One of the solutions is to have aspect-oriented techniques. It offers a promising approach for capturing such issues under verification. In the Literature we found very few testing techniques (NFR) proposed that too are application based as mentioned in Table [5].

\section{G. Automation}

Automation of process is necessary for speed up the development process. Not only requirements have to be carefully considered but they also have to be implemented. But there need to validate the implementation which can be easily done with the help of tool. Tool can potentially help agile software development teams in reasoning about and visually modeling NFRs as first-class artifacts early on during requirements gathering and analysis phases. It is better to create a simple and open toolkit that in turn can be adapted to a variety of projects and architectures [30]. Since there is need to handle NFRs automatically various tools have been proposed by researchers as enlisted in Table 6.

\section{H. Evaluation}

Evaluation means NFR importance degree assessment given by the expert's team on the basis of certain variables. Some important evaluation has been done in [12][81][105] [123]

\section{CONCLUSION AND FUTURE SCOPE}

NFR needs to look after starting from the early stages of software development. There is a need to chance the facet of NFRs while specifying it in SRS. Most of the literature is based on NFR elicitation and NFR Framework (informal approach). Some formal approach needs to be work out. According to Singh et al. number of models are available for Functional Requirements like Four Variable Model, COCOMO. Model and Reference Model etc. but no standardized model has been found opted for NFR [21][97]. It is due to informal presentation, NFR still a challenge in the field of requirement engineering.

To complete the specification for NFRs besides the four variables (NAT, REQ, IN, OUT) of four variable model new variable can be introduced or new model can be introduced from scratch for dealing with NFRs. Extensions to this model is also suggested in [77]. Similarly Reference Model can be extended for NFR as mentioned by Chung.[21].

As proposed in [97] NFR can be handled more concretely by MBT, some approach needs to be work out for handling real life situations.

Aspects help to achieve modularity in software development process. The use of AO to deal with NFR has already been proposed in [69].

In this paper we surveyed different aspects of NFR. We are likely to focus on formal modeling of NFR in future work. As it is the foremost challenge that need to be overcome if we want NFR to be quantified. Some of the issues related to NFR are mentioned in Table 7 found from the literature survey.

Table 5. Testing issues based on application

\begin{tabular}{|l|l|l|}
\hline Application & Issues & Solution Proposed \\
\hline Web Based application[89] & Verification during testing & $\begin{array}{l}\bullet \text { Metrics for the navigability } \\
\text { Load and Performance Testing }\end{array}$ \\
\hline $\begin{array}{c}\text { Quality verification of mobile phones } \\
{[76]}\end{array}$ & $\begin{array}{l}\text { Lack of Tool Support } \\
\text { Classify types of NFR }\end{array}$ & \begin{tabular}{c} 
Aspect-oriented techniques \\
\hline
\end{tabular} \\
\hline
\end{tabular}




\begin{tabular}{|c|c|c|}
\hline Source & Tool or Approach Name & Purpose \\
\hline Jan Ladiges etal.(2013) [62] & $\begin{array}{l}\text { Presented a set of non-functional } \\
\text { requirements on automated } \\
\text { production facilities. }\end{array}$ & $\begin{array}{l}\text { Approach used detects unintentional changes } \\
\text { in its behavior after performing modifications. }\end{array}$ \\
\hline $\begin{array}{l}\text { Farid and } \\
\text { Mitropoulos(2012)[33] }\end{array}$ & NORMATIC & $\begin{array}{l}\text { Modeling for Agile Processes (NORMAP) } \\
\text { Methodology. }\end{array}$ \\
\hline Cesare etal.(2012) [84] & Q4BPMN & $\begin{array}{l}\text { Non-Functional requirements can be directly } \\
\text { expressed within the BPMN model. }\end{array}$ \\
\hline Janne Merilinna etal.(2012)[75] & $\begin{array}{l}\text { Supported by a tool enables to } \\
\text { do that in the context of } \\
\text { Domain-Specific Modeling } \\
\text { (DSM). }\end{array}$ & $\begin{array}{l}\text { Bi-directional traceability link between } \\
\text { requirements and implementation is } \\
\text { maintained by NFR+ Framework. }\end{array}$ \\
\hline Kristoffer Dyrkorn(2008)[30] & $\begin{array}{l}\text { Present an open-source toolkit } \\
\text { that enables automated } \\
\text { testing of non-functional } \\
\text { requirements. }\end{array}$ & $\begin{array}{l}\text { Provides developers and project managers } \\
\text { with reports about the system under } \\
\text { development. }\end{array}$ \\
\hline Jane Cleland etal.(2007)[24] & $\begin{array}{l}\text { Technique for automating the } \\
\text { detection and classification of } \\
\text { non-functional Requirements. }\end{array}$ & $\begin{array}{l}\text { Approach is used to detect and classify } \\
\text { stakeholders' quality concerns across } \\
\text { requirements specifications containing } \\
\text { scattered and non-categorized } \\
\text { requirements }\end{array}$ \\
\hline $\begin{array}{l}\text { Lawrence Chung etal.(1996) } \\
\text { [22] }\end{array}$ & $\begin{array}{l}\text { Address tool support for the } \\
\text { change process }\end{array}$ & $\begin{array}{l}\text { Approach is based on existing NFR } \\
\text { Framework }\end{array}$ \\
\hline Al Balushi etal.(2007)[6] & ELICITO & Quality ontology-guided NFR elicitation tool \\
\hline
\end{tabular}

TABLE 7: NFR ISSUES

\begin{tabular}{|c|c|c|}
\hline S.No & Categories & Issues \\
\hline 1 & Identification and Specification & $\begin{array}{l}\text { - } \quad \text { Need to change the notion while specifying } \\
\text { NFR in RFP [39][40] } \\
\text { - } \quad \text { Formal Techniques [20][21] }\end{array}$ \\
\hline 2 & Elicitation & $\begin{array}{l}\text { - Aspect oriented documentation of attributes } \\
\text { and constraints [69][108] }\end{array}$ \\
\hline 3 & Formal Modeling & $\begin{array}{ll} & \text { Need to develop formal models like } \\
- & \text { Four Variable Model[21][77] } \\
\text { - } & \text { Reference model[21] }\end{array}$ \\
\hline 4 & Quantification & $\begin{array}{l}\text { - Formal models helps in quantification of } \\
\text { NFR [77][81][93] }\end{array}$ \\
\hline 5 & Testing & $\begin{array}{ll}\text { - } & \text { Clear Identification and } \\
& \text { Specification(Formal techniques) } \\
\text { - } & \text { AOP[69][97] } \\
\text { - } & \text { MBT[41][97] }\end{array}$ \\
\hline 6. & Automated Tool & $\begin{array}{l}\text { - Tool for empowering analyst by providing } \\
\text { knowledge repository, detecting NFR } \\
\text { conflict and to assess impact of NFRs in } \\
\text { early stages [5][30]. }\end{array}$ \\
\hline
\end{tabular}




\section{REFERENCES}

[1] Abdukalykov, R.; Hussain, I.; Kassab, M.; Ormandjieva, O., "Quantifying the Impact of Different Non-functional Requirements and Problem Domains on Software Effort Estimation," Software Engineering Research, Management and Applications (SERA), 2011 9th International Conference on , vol., no., pp.158,165, 10-12 Aug. 2011

[2] Abran A. , k. T. Al-Sarayreh, and J. J. Cuadrado-Gallego, 'A Standards-based Reference Framework for System Portability Requirements', Computer Standards and Interfaces Journal, Elsevier, Vol 35, 2013, pp. 380-395.

[3] Aburub, F., Odeh, M., Beeson, I.: Modelling non-functional requirements of business processes. Information and Software Technology 49, 1162-1171 (2007)

[4] Affleck A., Krishna, A. and Achuthan, N.R. (2013). Optimal Selection of Operationalizations for Non-Functional Requirements. In Proc. Conceptual Modelling 2013 (APCCM 2013) Adelaide, Australia. CRPIT, 143. Ferrarotti, F. and Grossmann, G. Eds., ACS. 69-78

[5] Affleck, A.; Krishna, A., "Supporting quantitative reasoning of non-functional requirements: A process-oriented approach," Software and System Process (ICSSP), 2012 International Conference on , vol., no., pp.88,92, 2-3 June 2012.

[6] Al Balushi T. H., P. R. F. Sampaio, D. Dabhi, and P. Loucopoulos, "ElicitO: a quality ontology-guided NFR elicitation tool," in Proceedings of the 13th international working conference on Requirements engineering: foundation for software quality (REFSQ'07), Springer-Verlag, Berlin, Heidelberg, pp. 306-319, 2007.

[7] Allen H. Dutoita and Barbara Paechb Rationale-Based Use Case Specification Requirements Eng (2002) 7:3-19 2002 SpringerVerlag London Limited

[8] Ameller, D.; Ayala, C.; Cabot, J.; Franch, X., "How do software architects consider non-functional requirements: An exploratory study," Requirements Engineering Conference (RE), 2012 20th IEEE International , vol., no., pp.41,50, 24-28 Sept. 2012

[9] Anandha G.S. Mala and G.V. Uma, "Elicitation of non functional requirement preference for actors of Usecase from domain model," PKAW 2006, LNAI 4303, Springer-Verlag Berlin Heidelberg, pp. 238-243, 2006.

[10] Ben A. Hamida, A. Bertolino, A. Calabrò, G. De Angelis, N. Lago, and J. Lesbegueries, "Monitoring service choreographies from multiple sources, " in Proc. of 4th International Workshop on Software Engineering for Resilient Systems (SERENE 2012), ser. LNCS, vol. 7527. Springer, Sept. 2012, pp. 134-149.

[11] Berenbach Brian and Mark Gall.(2006) Toward a Unified Model for Requirements Engineering. ICGSE, 0:237-238.

[12] Berntsson Svensson, R., Gorschek, T., Regnell, B., Torkar, R., Shahrokni, A., Feldt, R., Aurum, A.: Prioritization of quality requirements state of practice in eleven companies. In: RE 2011, pp. 69-78. IEEE (2011)

[13] Bhatti Shahid Nazir, ACM (Software Engineering Notes) Journal, "Deducing the complexity to quality of a system using UML", ISSN: 0163-5948, Volume 34, Pages 1-7, USA.

[14] Boehm B. et al. (1976). Quantitative Evaluation of Software Quality. Proceedings of the 2nd IEEE International Conference on Software Engineering. 592-605.

[15] Boonma, P.; Suzuki, J., "Middleware Support for Pluggable Non-Functional Properties in Wireless Sensor Networks," Services - Part I, 2008. IEEE Congress on , vol., no., pp.360,367, 6-11 July 2008
[16] Borges R. and A. Mota, Integrating UML and Formal Methods, Electronic Notes in Theoretical Computer Science, 184, pp. 97112, 2003

[17] Bret Pettichord. (October 2002), Design for Testability ,Pacific Northwest Software Quality Conference, Portland, Oregon.

[18] Cancila D. , R. Passerone , T. Vardanega and M. Panunzio "Toward correctness in the specification and handling of nonfunctional attributes of high-integrity real-time embedded systems", IEEE Trans. Ind. Informat., vol. 6, no. 2, pp.181 1942010

[19] Casamayor A, Godoy D, Campo M (2009) Semi-supervised classification of non-functional requirements: an empirical analysis. Rev Iberoam Intel Artif 13(44): 35-45. doi:10.4114/ia.v13i44.1044

[20] Casamayor A, Godoy D, Campo M (2010) Identification of nonfunctional requirements in textual specifications: a semisupervised learning approach. Inform Softw Technol 52(4): 436-445. doi:10.1016/j.infsof.2009.10.010

[21] Chung L. , Kendra Cooper, Anna Yi, Developing adaptable software architectures using design patterns: an NFR approach, Computer Standards \& Interfaces, v. 25 n.3, p.253-260, June $\underline{2003}$

[22] Chung L. a, Brian A. Nixon b and Eric Yu c Dealing with Change: An Approach Using Non-functional Requirements 1 Requirements Eng (1996) 1:238-260-9 1996 Springer-Verlag London Limited

[23] Chung, L., Nixon, B., Yu, E. and Mylopoulos,J. (2000) "NonFunctional Requirements in Software Engineering": Boston Kluwer Academic Publishers.

[24] Cleland-Huang Jane, Raffaella Settimi, Xuchang Zou , Peter Solc Automated classification of non-functional requirements Requirements Eng (2007) 12:103-120 Springer-Verlag London Limited 2007

[25] Curtis B. in blog for Consortium for IT Software Quality http://it-cisq.org/non-functional-requirements-be-here/

[26] Cysneiros Luiz Marcio and Julio Cesar Sampaio Leite (2001). Using UML to reflect Non-functional Requirements. In CASCON, page 2.

[27] Cysneiros Luiz Marcio, Member,Julio Cesar Sampaio do Prado Leite, Member,(MAY 2004) Nonfunctional Requirements:From Elicitation to Conceptual Models, IEEE TRANSACTIONS ON SOFTWARE ENGINEERING, VOL. 30, NO. 5.

[28] do Prado Sampaio.T. Borgida et al. (2009). On Non-Functional Requirements in Software Engineering (Eds.): Mylopoulos Festschrift, LNCS 5600, pp. 363-379, 2009.@ Springer-Verlag Berlin Heidelberg.

[29] Dobson G., S. Hall, and G. Kotonya. A domain-independent ontology for non-functional requirements. In ICEBE '07: Proceedings of the IEEE International Conference on e-Business Engineering, pages 563-566, Washington, DC, USA, 2007. IEEE Computer Society.

[30] Dyrkorn K. and F. Wathne, "Automated testing of nonfunctional requirements," in Companion to the 23rd ACM SIGPLAN conference on Object-oriented programming systems languages and applications, New York, NY, USA, 2008.

[31] Emadi, S.; Shams, F., "An approach to non-functional requirements analysis at software architecture level," Computer and Information Technology, 2008. CIT 2008. 8th IEEE International Conference on, vol., no., pp.736,741, 8-11 July 2008

[32] Fabbrini F., M.Fusani, S.Gnesi, G.Lami "Quality Evaluation of Software Requirement Specifications", Proc of Software \& Internet Quality Week 2000 Conference., San Francisco, CA May 31-June 2 2000, Session 8A2. 
[33] Farid W.M. and F. J. Mitropoulos, "Novel lightweight engineering artifacts for modeling non-functional requirements in agile processes", Proc. IEEE SoutheastCon 2012 (SoutheastCon 2012), Mar. 2012.

[34] Filieri A., C. Ghezzi, and G. Tamburrelli, "A formal approach to adaptive software: continuous assurance of non-functional requirements," Formal Aspects of Computing, vol. 24, no. 2, pp. 163-186, 2012.

[35] Franch X. "Systematic Formulation of Non-functional Characteristics of Software," Proc. 3rd IEEE Int',1 Conf. Requirements Eng. (ICRE), IEEE CS Press, Los Alamitos, Calif., 1998, pp. 174-181.

[36] Friess, Wolfgang; Kubica, Stefan, "Implementing NonFunctional Requirements (29 March 2006) $\hat{A}_{i}$ A Layered Modeling Approach," Model-Based Testing, ITGA FA 6.2 Workshop on and GI/ITG Workshop on Non-Functional Properties of Embedded Systems, 2006 13th GI/ITG Conference -Measuring, Modelling and Evaluation of Computer and Communication (MMB Workshop), vol., no., pp.1,7, 27-

[37] Galster M. and E. Bucherer, "A Taxonomy for Identifying and Specifying Non-Functional Requirements in Service-Oriented Development," IEEE Congress on Services, IEEE Press, 2008, pp. 345-352.

[38] Ghezzi C.and G. Tamburrelli. Reasoning on non-functional requirements for integrated services. In RE'09, Atlanta, USA, 2009.

[39] Glinz M., "Rethinking the notion of non-functional requirements," in Third World Congress for Software Quality, Munich, Germany, 2005, pp. 55-64.

[40] Glinz, M. "On non-functional requirements," in $15^{\text {th }}$ IEEE International Requirements Engineering Conference (RE '07), 2007, pp. 21-26.

[41] Gonzalez-Huerta, J., Insfran, E., Abrahao, S., McGregor, J.D.: Non-functional Requirements in Model-Driven Software Product Line Engineering. In: 4th Int. Workshop on Nonfunctional System Properties in Domain Specific Modeling Languages, Insbruck, Austria (2012)

[42] Grady R and Caswell D, Software Metrics: Establishing a Company-wide Program, Prentice Hall, Englewood Cliffs, New Jersey, 1987

[43] Grimshaw D.J., W. Godfrey and G.W. Draper, "Non-Functional Requirements Analysis: Deficiencies in Structured Methods," Information \&, Software Technology, vol. 43, no. 11, pp. 629-635, 2001.

[44] Gross Daniel and Eric Yu From Non-Functional Requirements to Design through Patterns Requirements Eng (2001) 6:18-36 Springer-Verlag London Limited

[45] Heng Kuang; Ormandjieva, O., "Self-Monitoring of Nonfunctional Requirements in Reactive Autonomic Systems Framework: A Multi-agent Systems Approach," Computing in the Global Information Technology, 2008. ICCGI '08. The Third International Multi-Conference on, vol., no., pp.186,192, July 27 2008-Aug. 12008

[46] Hosono S., T. Hara, Y. Shimomura and T. Arai, Prioritizing Service Functions with Non-Functional Requirements, CIRP Industrial Product-Service Systems Conf., 2010, pp.133-140.

[47] http://en.wikipedia.org/

[48] Huang J.C., R. Settimi, X. Zou, and P. Solc, "The detection and classification of non-functional requirements with application to early aspects," Center for Requirements Engineering, School of Computer Science, Telecommunications and Information Systems, DePaul Üniversity, In 14th IEEE International Requirements Engineering Conference (RE'06), 2006.
[49] Hussein, M.; Zulkernine, M., "UMLintr: a UML profile for specifying intrusions," Engineering of Computer Based Systems, 2006. ECBS 2006. 13th Annual IEEE International Symposium and Workshop on, vol., no., pp.8 pp.,288, 27-30 March 2006

[50] IEEE (1993). IEEE Recommended Practice for Software Requirements Specifications.IEEE Standard 830-1993.

[51] In H., and B. W. Boehm, "Using win-win quality requirements management tools: a case study", Annals Software Eng. 11(1): pp. 141-174, 2001.

[52] ISO/IEC 9126-1:2001(E): Software Engineering - Product Quality - Part 1: Quality Model(2001)

[53] J"urjens Jan.(2002) UMLsec: Extending UML for Secure Systems Development. In UML '02: Proceedings of the 5th International Conference on The Unified Modeling Language, pages 412-425, London, UK, Springer-Verlag.

[54] Jacobs S., "Introducing Measurable Quality Requirements: A Case Study," Proc. Fourth Int',1 Symp. Requirements Eng., pp. 172-179, 1999.

[55] Jane Cleland-Huang, Toward improved traceability of nonfunctional requirements, Proceedings of the 3rd international workshop on Traceability in emerging forms of software engineering, November 08-08, 2005, Long Beach, California

[56] Jaramillo A.F., "Non-functional requirements elicitation from business process models", IEEE Doctoral Paper 2011.

[57] Jureta, I.J., Faulkner, S., Schobbens, P.-Y.: A more expressive softgoal conceptualization for quality requirements analysis. In: Embley, D.W., Olivé, A., Ram, S. (eds.) ER 2006. LNCS, vol. 4215, pp. 281-295. Springer, Heidelberg (2006)

[58] Kaiya H., A. Osada, and K. Kaijiri, "Identifying stakeholders and their preferences about NFR by comparing use case diagrams of several existing systems," IEICE - Trans. Inf. Syst. E91-D, pp. 897-906, April 2008.

[59] Kassab, M.; Ormandjieva, O.; Daneva, M., "Relational-model based change management for non-functional requirements: Approach and experiment," Research Challenges in Information Science (RCIS), 2011 Fifth International Conference on, vol., no., pp.1,9, 19-21 May 2011

[60] Kavakli E. and P. Loucopoulos, "Goal Modeling in Requirements Engineering: Analysis and Critique of Current Methods", Information Modeling Methods and Methodologies: Advanced Topics of Database Research, IGI Publishing, 2005, pp. 102-124.

[61] L. Xu, H. Ziv, and T. A. Alspaugh, et. al., "An architectureal pattern for non- functional dependability requirements". Systems \& Software, Vol.79, No. 10, pp.1370-1378.

[62] Ladiges, J.; Fay, A.; Haubeck, C.; Lamersdorf, W., "Operationalized definitions of non-functional requirements on automated production facilities to measure evolution effects with an automation system," Emerging Technologies \& Factory Automation (ETFA), 2013 IEEE 18th Conference on , vol., no., pp.1,6, 10-13 Sept. 2013

[63] Ledru Y., R. Laleau, M. Lemoine, S. Vignes, D. Bert, V. Donzeau-Gouge, C. Dubois, and F. Peureux. An attempt to combine UML and formal methods to model airport security. In Forum of the 18th International Conference on Advanced Information Systems Engineering, pages 47-50, Luxembourg, 2006.

[64] Lera, I.; Puigjaner, R.; Semantic Layered Architecture to integrate FR/NFR in Software Performance Engineering. WOSP/SIPEW 2010, poster

[65] Liu Xiaoqing; Azmoodeh, M.; Georgalas, N., "Specification of non-functional requirements for contract specification in the NGOSS framework for quality management and product 
evaluation,"Software Quality, 2007. WoSQ'07: ICSE Workshops 2007. Fifth International Workshop on, vol., no., pp.,, 20-26 May 2007

[66] Liu, (2010) "Ontology-Based Conflict Analysis Method in Non-Functional Requirements" 978-0-7695-4147-1/10 IEEE.

[67] Livson B.U., A practical approach to software quality assurance, ACM SIGSOFT Software Engineering Notes, v.13 n.3, p.45-48, July 1988

[68] Lodderstedt Torsten, David A. Basin, and J"urgen Doser.(2002) SecureUML: A UMLBased Modeling Language for ModelDriven Security. In UML '02: Proceedings of the 5th International Conference on The Unified Modeling Language, pages 426-441, London, UK, 2002. Springer-Verlag.

[69] M.A. Wehrmeister, E. P. Freitas, C. E. Pereira, and F. Wagner, "An Aspect-Oriented Approach for Dealing with NonFunctional Requirements in Model-Driven Development of Distributed Embedded Real-Time Systems", 10th IEEE Symposium on Object Oriented Real-Time Distributed Computing, 2007.

[70] Mairiza D.et al. (2010), An investigation into the notion of nonfunctional requirements, Proceedings of SAC'10, Pages 311317, ACM New York, NY, USA

[71] Matoussi, R. Laleau. (October 2008) A Survey of NonFunctional Requirements in Software Development Proces, Technical Report TR-LACL.

[72] McCall, J.A., Matsumoto, M.T. (1980). Software Quality Measurement Manual, Vol. II. Rome Air Development Center, RADC-TR-80-109-Vol-2.

[73] Mehta, R. and Chung, L. "Dependencies among Architectural Components and their Impacts towards Non-Functional Requirements," IEEE Software, Special Issue on Twin Peaks of Requirements and Architecture(2013).

[74] Mens, Tom; Wermelinger, Michel; Ducasse, Stane; Demeyer, Serge; Hirschfeld, Robert and Jazayeri, Mehdi (2005). Challenges in Software Evolution. In $8^{\text {th }}$ conference on on Principles ofSoftware Evolution, p.13-22, September 0506, 2005

[75] Merilinna Janne etal. NFR+ framework method to support bidirectional traceability of non-functional requirements SpringerVerlag 2012

[76] Metsa, J.; Katara, M.; Mikkonen, T., "Testing Non-Functional Requirements with Aspects: An Industrial Case Study," Quality Software, 2007. QSIC '07. Seventh International Conference on , vol., no., pp.5,14, 11-12 Oct. 2007

[77] Miller, S.P. and Tribble, A.C. 2001. Extending the FourVariable Model to Bridge the System-Software Gap. In Proceedings of the Twentith IEEE/AIAA Digital Avionics Systems Conference (DASC'01).

[78] Mylopoulos J., L. Chung, B. Nixon (1992). Representing and Using Nonfunctional Requirements: A Process- Oriented Approach. IEEE Transactions on Software Engineering 18, 6 (June 1992). 483-497.

[79] Nguyen, Q.L., "Non-functional requirements analysis modeling for software product lines," Modeling in Software Engineering, 2009. MISE '09. ICSE Workshop on , vol., no., pp.56,61, 17-18 May 2009

[80] Norian, M., Bagheri, E., Du, W.: Non-functional Properties in Software Product Lines: A Taxonomy for classification. In proc. of 24th International Conference on Software Engineering and Knowledge Engineering (SEKE 2012), 2012.

[81] Okubo, T.; Yoshioka, N.; Kaiya, H., "Security Driven Requirements Refinement and Exploration of Architecture with Multiple NFR Points of View," High-Assurance Systems
Engineering (HASE), 2014 IEEE 15th International Symposium on , vol., no., pp.201,205, 9-11 Jan. 2014

[82] Osterweil, L.J., "A Future for Software Engineering?," Future of Software Engineering, 2007. FOSE '07, vol., no., pp.1,11, 2325 May 2007.

[83] P. Botella, X. Burgués, X. Franch, M. Huerta, G. Salazar. "Modelling Non-Functional Requirements". Proceedings of Jornadas Ingeniería de Requisitos Aplicados (JIRA), 2001

[84] Pavlovski C.J. J. and Zou, "Non-Functional Requirements in Business Process Modeling", Proc. of $5^{\text {th }}$ Asia-Pacific Conference on Conceptual Modelling, Wollongong, NSW, Australia. CRPIT, 2008, Vol. 79, pp. 103-112.

[85] Poort, E.R., Key, A., de With, P.H.N., van Vliet, H.: Issues Dealing with Non-Functional Requirements across the Contractual Divide. In: WICSA/ECSA 2012, pp. 315-319 (2012).

[86] Pressman, R. S. (2005). Software Engineering: A Practitioner's Approach (6th ed.). New York:- McGraw-Hill Publication.

[87] Rao Ananda and M.Gopichand (2011)“Four Layered Approach to non-functional requirements Analysis" IJCSI International Journal of Computer Science Issues, Vol. 8, Issue 6, No 2.

[88] Roman, G.-C.: A TaxonoTaxonomy of Current Issues in Requirements Engineering. IEEE Computer, 14-21 (April 1985)

[89] Romano Breno, Gláucia Braga e Silva, Henrique Fernandes de Campos, Ricardo Godoi Vieira, Adilson Marques da Cunha, Fábio Fagundes Silveira, Alexandre Carlos Brandão Ramos, "Software Testing for Web-Applications Non-Functional Requirements," itng, pp.1674-1675, 2009 Sixth International Conference on Information Technology: New Generations, 2009

[90] Rosa N., P. Freire Cunha, and G. Ribeiro Justo. An Approach for Reasoning and Refining Non-Functional Requirements. Journal of the Brazilian Computer Society, 10:62-84, 2004. 10.1007/BF03192354.

[91] Saadatmand, M., Cicchetti, A., Sjödin, M.: Uml-based modeling of non-functional requirements in telecommunication systems. In: The Sixth International Conference on Software Engineering Advances, ICSEA 2011 (2011)

[92] Sadana, V.; Liu, X.F., "Analysis of Conflicts among NonFunctional Requirements Using Integrated Analysis of Functional and Non-Functional Requirements," Computer Software and Applications Conference, 2007. COMPSAC 2007. 31st Annual International, vol.1, no., pp.215,218, 24-27 July 2007

[93] Sadiq, J.; Mohsin, A.; Arif, F., "Quantifying Non-functional Requirements in Service Oriented Development," Frontiers of Information Technology (FIT), 2011 , vol., no., pp.224,229, 1921 Dec. doi: 10.1109/FIT.2011.48

[94] Saito Yasuhiro," Evaluation of Non Functional Requirements in a Request For Proposal (2012)"in Seventh International Conference on Software Process and Product Measurement, 978-0-7695-4840-1/12 IEEE

[95] Salazar-Zárate G., P. Botella. "Use of UML for Non-Functional Aspects". Proceedings of 13th International Conference Software \& Systems Engineering and their Applications (ICSSEA), 2000.

[96] Schmeling, B.; Charfi, A.; Thome, R.; Mezini, M., "Composing Non-functional Concerns in Web Services," Web Services (ECOWS), 2011 Ninth IEEE European Conference on, vol., no., pp.73,80, 14-16 Sept. 2011

[97] Singh Pratima and Anil Kumar Tripathi, (July 2012) "ISSUES IN TESTING OF SOFTWARE WITH NFR", International Journal of Software Engineering \& Applications (IJSEA), Vol.3, No.4. 
[98] Snook Colin, Michael Butler, UML-B: Formal modeling and design aided by UML, ACM Transactions on Software Engineering and Methodology (TOSEM), v.15 n.1, p.92-122, January 2006

[99] Soltani Samaneh, Mohsen Asadi, Dragan Gašević, Marek Hatala , Ebrahim Bagheri, Automated planning for feature model configuration based on functional and non-functional requirements, Proceedings of the 16th International Software Product Line Conference, September 02-07, 2012, Salvador, Brazil

[100] Sommerville (2006). $6^{\text {th }}$ edition Ed. Addison Wesley,

[101] Song Xiping; Hwong, B.; Ros, J., "Lessons from Developing Nonfunctional Requirements for a Software Platform," Software, IEEE, vol.29, no.2, pp.74,80, March-April 2012

[102] Subramanian Nary , Lawrence Chung, Software architecture adaptability: an NFR approach, Proceedings of the 4th International Workshop on Principles of Software Evolution, September 10-11, 2001, Vienna, Austria

[103] Supakkul Sam and Lawrence Chung.(2004) Integrating FRs and NFRs: A Use Case and Goal Driven Approach. Proc. SERA 04, pages 30-37,

[104] Taeg Jung Keo; Gil-Haeng Lee, "A systematic software development process for non-functional requirements," Information and Communication Technology Convergence (ICTC), 2010 International Conference on, vol., no., pp.431,436, 17-19 Nov. 2010

[105] Thakurta R (2012) A framework for prioritization of quality requirements for inclusion in a software project. Software quality journal. Springer, New York

[106] Tonu Subrina A. and Ladan Tahvildari. Towards a Framework to IncorporateIn Proceedings of IEEE WCRE Workshop on Reverse Engineering to Requirements (RETR), Pittsburgh, Pennsylvania, USA, pages 13-18, November 2005.

[107] Tsadimas, A.; Nikolaidou, Mara; Anagnostopoulos, D., "Handling Non-functional Requirements in Information System Architecture Design," Software Engineering Advances, 2009. ICSEA '09. Fourth International Conference on, vol., no., pp.59,64, 20-25 Sept. 2009

[108] Ullah Saeed, Muzaffar Iq bal, Aamir Mehmood Khan,( 2011) A Survey on Issues in Non-Functional Requirements Elicitation Computer Networks and Information Technology (ICCNIT), 2011 International Conference on 978-1-61284-9416/11 IEEE.

[109] Umar, M.; Khan, N.A., "Analyzing Non-Functional Requirements (NFRs) for software development," Software Engineering and Service Science (ICSESS), 2011 IEEE 2nd International Conference on , vol., no., pp.675,678, 15-17 July 2011

[110] Van Lamsweerde Axel. Goal-Oriented Requirements Engineering: A Guided Tour. In RE '01: Proceedings of the Fifth IEEE International Symposium on Requirements Engineering (RE '01), page 249, Washington, DC, USA, 2001. IEEE Computer Society.

[111] Vanhanen J., M.V.Mantyla, and J. Ithonen, " Lightweight elicitation and analysis of software product quality goals a multiple industrial case study," Third International Workshop on Software Product Management (IWSPM), pp. 42-52, September 2009.

[112] vensson, R.B.; Gorschek, T.; Regnell, B.; Torkar, R.; Shahrokni, A.; Feldt, R.; Aurum, A., "Prioritization of quality requirements: State of practice in eleven companies," Requirements Engineering Conference (RE), 2011 19th IEEE International, vol., no., pp.69,78, Aug. 29 2011-Sept. 22011

[113] Wagner, S.; Deissenboeck, F., "An Integrated Approach to Quality Modelling," Software Quality, 2007. WoSQ'07: ICSE Workshops 2007. Fifth International Workshop on, vol., no., pp.1,1, 20-26 May 2007

[114] Wei B., Z. Jin, and L. Liu, "A formalism for extending the NFR Framework to support the composition of the goal trees,"in 17th Asia Pacific Software Engineering Conference, 2010, pp. 23-32

[115] Wei B.and Z. Jin, "Characterizing the implementation of software non-functional requirements from probabilistic perspective,"in COMPSAC, 2011, to appear.

[116] Wen C. Too, Sa'adah Hassan, Jamilah Din, and Abdul Azim Abd. Ghani, Towards Improving NFR Elicitation in Software Development, International Journal of Information Technology \& Computer Science ( IJITCS ) (ISSN No : 20911610 )Volume 7 : No : 1 : Issue on January / February, 2013

[117] Xu Lihua, Hadar Ziv, Debra Richardson, and Zhixiong Liu. Towards Modeling Non-Functional Requirements in Software Architecture. 2005.

[118] Ye Fei; Zhu Xiaodong, "An XML-Based Software NonFunctional Requirements Modeling Method," Electronic Measurement and Instruments, 2007. ICEMI '07. 8th International Conference on , vol., no., pp.2-375,2-380, Aug. 16 2007-July 182007

[119] Yin Bin, Jin Zhi, Chen Xiaohong An approach for selecting implementation strategies of non-functional requirements in Proceedings of the Fourth Asia-Pacific Symposium on Internetware Article No. 20 ACM New York, NY, USA @2012.

[120] Yrjönen A, Merilinna J (2010) Tooling for the full traceability of non-functional requirements within model-driven development. In: 6th ECMFA traceability workshop (ECMFATW'10), Paris, 15 June 2010

[121] Yu E., "Towards modelling and reasoning support for early-phase requirements engineering," Proc. of the 3rd IEEE International Symposium on Requirements Engineering (RE' 97), pp. 226-235, 1997.

[122] Zheng X.; Xiaomei Liu; Shulin Liu, "Use Case and Nonfunctional Scenario Template-Based Approach to Identify Aspects," Computer Engineering and Applications (ICCEA), 2010 Second International Conference on , vol.2, no., pp.89,93, 19-21 March 2010

[123] Zhu Liming and Ian Gorton. UML Profiles for Design Decisions and Non- Functional Requirements. In 2ndIntl. Workshop on SHAringand Reusing architectural Knowledge, 2007.

[124] Zhu Ming-Xun, Xin-Xing Luo , Xiao-Hong Chen Desheng Dash Wu, A non-functional requirements tradeoff model in Trustworthy Software, Information Sciences: an International Journal, 191, p.61-75, May, 2012

[125] Zou J. and C.J. Pavlovski, "Modeling Architectural Non Functional Requirements: From Use Case to Control Case", Proc. of IEEE International Conference on e-Business Engineering (ICEBE '06), Shanghai China, 2006, pp. 315-322.

[126] Zschaler S., "Towards a Semantic Framework for Nonfunctional Specifications of Component-Based Systems", Proc. 30th EUROMICRO Conf., Rennes, France, Aug./Sep. 2004, pages 92-99, IEEE Computer Science, Sept. 2004.

[127]Zschaler, S.: Formal specification of non-functional properties of component-based software systems: A semantic framework and some applications thereof. Software and Systems Modelling (SoSyM) 9, 161-201 (2009) 